This item was submitted to Loughborough's Research Repository by the author.

Items in Figshare are protected by copyright, with all rights reserved, unless otherwise indicated.

\title{
Evaluating gains from mergers in a non-parametric public good model of police services.
}

PLEASE CITE THE PUBLISHED VERSION

LICENCE

CC BY-NC-ND 4.0

\section{REPOSITORY RECORD}

Simper, Richard, and Thomas G. Weyman-Jones. 2019. "Evaluating Gains from Mergers in a Non-parametric Public Good Model of Police Services.". figshare. https://hdl.handle.net/2134/1685. 
This item was submitted to Loughborough's Institutional Repository by the author and is made available under the following Creative Commons Licence conditions.

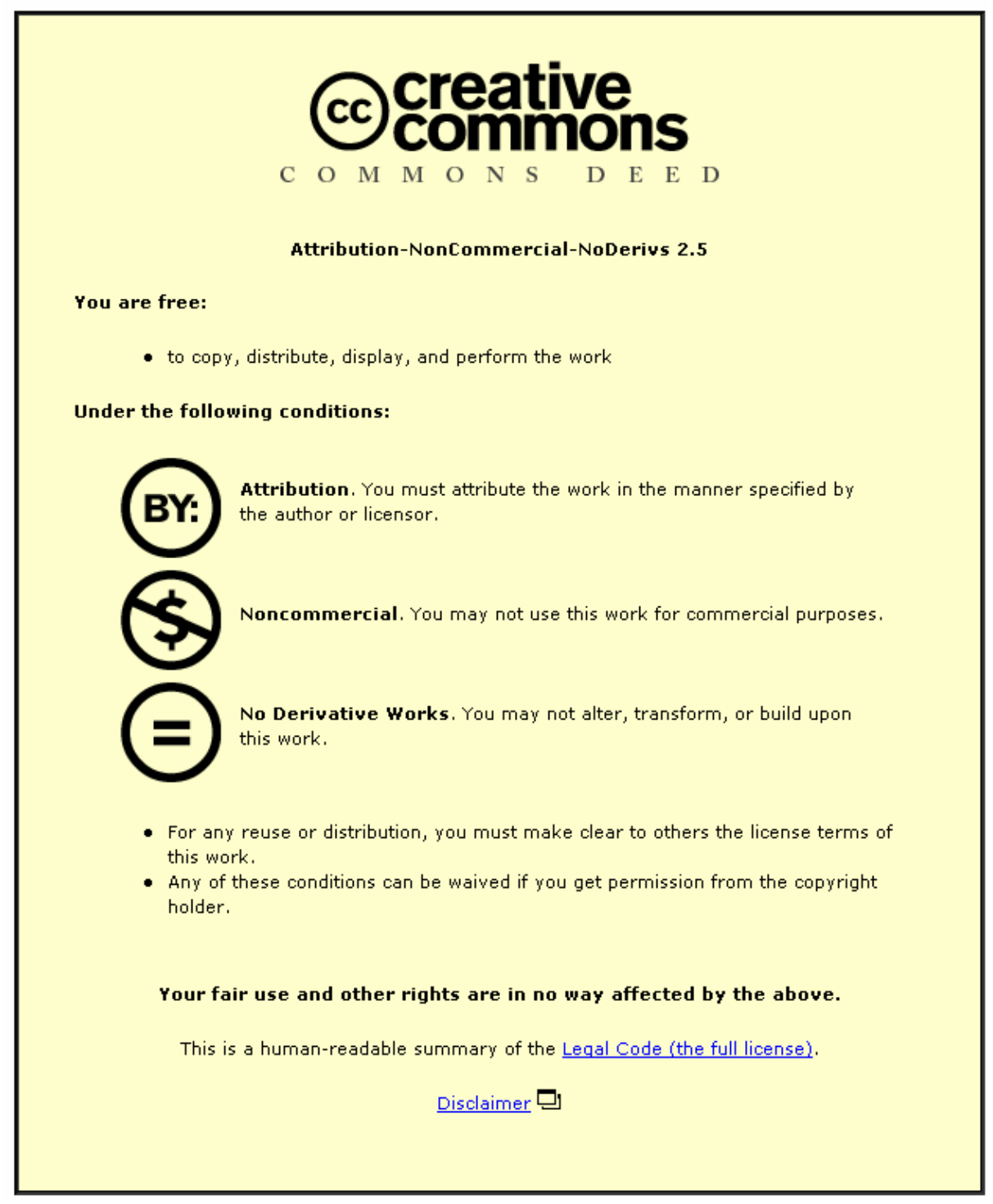

For the full text of this licence, please go to: http://creativecommons.org/licenses/by-nc-nd/2.5/ 


\title{
Evaluating Gains from Mergers in a Non-Parametric Public Good Model of Police Services.
}

\author{
Richard SIMPER* and Thomas WEYMAN-JONES \\ Department of Economics, Loughborough University, Loughborough, England, LE11 \\ $3 T U$.
}

\begin{abstract}
The merger of police services in the UK has been suggested on the grounds that efficiency improvements will be possible. This paper applies a public good model of the police service to evaluate the potential efficiency gains from mergers of police services in England and Wales. We construct a dataset that reflects the public good nature of police service and allows for the exogenous imposition by Government of the level of police service budgets. Our main finding is that English and Welsh police force mergers could lead to increases in police staff resource efficiencies between $10 \%$ and $70 \%$.
\end{abstract}

JEL number: C14, H41, L30

Keywords: data envelopment analysis, police service efficiency, public goods

\footnotetext{
* Corresponding author: Richard Simper. email: r.simper@lboro.ac.uk. Tel: +44 (0) 150922 2701, Fax: +44 (0) 1509223910
} 


\section{INTRODUCTION}

Since the 1960s and the introduction of efficiency measurement techniques of police forces, successive UK governments have tried to ensure that public funds were used in an 'economic, efficient and effective' manner. ${ }^{1}$ The 'experiments' in measuring the performance of police forces during the 1960s and 1970s led to many revisions, from input-output 'operations management' techniques to scorecards (for a discussion of early performance reforms see for example, Stephens, 1994; Sullivan, 1998; and Drake and Simper, 2001). In the 1980s and 1990s performance indicators were introduced to analyse performance, and then in the second term of the new Labour government econometric techniques were advocated in the Spottiswoode (2000) report "Improving Police Performance". It is interesting to note that Spottiswoode advocated the use of Data Envelopment Analysis (DEA) and Stochastic Frontier Analysis (SFA) as this would allow interactions between inputs and outputs in the policing function, thereby bypassing any of the failings in previous performance measurement programmes (which did not take costs explicitly in to account).

However, in the third term of the new Labour government, the Home Office elected not to follow the recommendations of the Spottiswoode and promoted the use of an alternative 'Spidergram' approach in addition to Best Value Performance Indicators (BVPIs) (see for example, Drake and Simper, 2005, and The National Policing Plans 2003/04 and 2004/05). These two techniques were again wholly output (outcome) based measurement programmes allowing the public to determine, using simple diagrams, whether their local police force could satisfy six domain

\footnotetext{
${ }^{1}$ Indeed The Police Act 1964, s. 4.(1) states that "it shall be the duty of the Police Authority for every police area for which a police force is required to be maintained by section 1 of this Act to secure the maintenance of adequate and efficient police force for the area, and to exercise for that purpose the powers conferred on a police authority by this Act.” (our emphasis) The managerialism of the police service, coming from the Home Office Circular 114/83 also introduced the three E's: Economy, Efficiency and Effectiveness. Subsequent legislation, the Police and Magistrates Court Act 1994 replaced 'adequate and efficient' with 'efficient and effective' and finally The Local Government Act 1999 introduced Best Value, such that: "A Best Value authority must make arrangements to secure continuous improvement in the way in which its functions are exercised, having regard to a combination of economy, efficiency and effectiveness" (our emphasis).
} 
criteria's promoted on certain policing functions as specified by the Home Office. $^{2}$ The six domains in the 'Spidergrams' were: 'reducing crime', 'investigating crime', 'promoting public safety'; 'citizen focus,' and 'resource usage.' Hence, the aim of the 'Spidergrams' was that these domains would show whether an individual police force was below a specified Home Office target or below an average obtained from a set of reference forces (known as 'Most Similar Forces' (MSFs)). That is, in line with the Police Reform Act 2002, police forces would be assessed with respect to their performance of these six domains, although, their success or failure could not be based on the costs incurred or resources redeployed. ${ }^{3}$

These 'Spidergrams' were consistent with the methodology introduced by the UK government in connection with 'Best Value Performance Indictors' (BVPIs) (see DETR, 1999). They did not, however, follow the stated public policy aim of Value for Money (VFM). In the Home Office report “What Price Policing?”, for example, it was stated that "police managers need to work harder to ensure that VFM is achieved, for competitive pressure has to be created internally. The costing of activity with subsequent measurement and comparison of performance provide the means by which such encouragement is given” (HMIC Report, 1998, paragraph 10.) Furthermore, by not linking outcomes to resource utilisation and costs, the Home Office was also not following the recommendation given in Spottiswoode where it stated that, "Best Value is the central plank in the drive to improve police performance. A systematic measure of police efficiency - where "efficiency" is a measure of the polices performance in meeting their overarching aims and objectives for the money spent is crucial if Best Value is to work effectively,” (page 4). As alluded to previously, the report further advanced the use of nonparametric and parametric techniques such that

\footnotetext{
${ }^{2}$ UK policing is split into 3 distinct political jurisdictions, The Police Service of Northern Ireland, The Police forces of Scotland, and those stationed in England and Wales. This paper is concerned with the latter group of which the Home Office is responsible directly for their 'economy, efficiency and effectiveness' in policing matters.

${ }^{3}$ Indeed, instead of differential targets as proposed in Spottiswoode (2000), the Home Office criteria of forces "meeting an annual target of savings/efficiency gains equivalent to $2 \%$ of their annual budget” is to continue (National Policing Plan 2003/04, page 39).
} 
"this approach would also mean that "efficiency" is about finding ways of improving the performance delivered for the money that each authority and force has” (page 5). ${ }^{4}$

However, even though there are some failings by not implementing the Spottiswoode recommendations on measuring efficiency, the UK government has considered any increases obtained in the 'Value for Money' programme had possibly reached a 'frontier'. That is, after seven successful years of increasing police efficiency the Home Office has posited that any more future efficiency could be obtained through force mergers releasing additional scale, scope and further $\mathrm{x}$ efficiencies. Hence, the Home Office began in 2005 consultative studies to determine possible merger efficiencies amongst police forces. Indeed, as stated in the initial report, Her Majesties Inspectorate of Constabulary (HMIC) found that, "the current structure and efficiency regime is not designed to yield a step change in VFM, nor easily support workforce modernisation. Process and procurement reform might though be accelerated by the consolidation of forces in one form or another" (paragraph 30, page. 11). Further, they find that "the NPV (Net Present Value) of merger savings and productivity gains could amount to £2,250 million” (paragraph. 31, page. 11, O’Conner, 2005).

The idea that there maybe efficiencies found in merging police forces is not new, see empirical studies by Cameron (1989) and Drake and Simper (2000). However, we believe that this is the first paper in this area to consider mergers by applying a non-parametric methodology for the measurement of the gains from actual mergers. Our findings do not provide a complete cost-benefit analysis of the proposed mergers, since we do not calculate the transaction or adjustment costs of the mergers, nor do we compute the discounted present value of the net efficiency gains. Instead, we compare two different comparative static equilibria: one is the existing organisational structure of police services, the other is a set of different hypothetical merged structures in which the technical efficiency with which observed inputs are transformed to outputs is evaluated relative to the existing structure. We describe a

\footnotetext{
${ }^{4}$ Indeed, the UK Government press release associated with the Spottiswoode report, states, "this report identifies a systematic, comprehensive measure of relative police efficiency for the first time. It recommends that efficiency estimates are used to set differentiated targets for forces, reflecting their room for improvement compared to the best forces. This means that the targets would better reflect the current performance of each force and the environment they work within.” PSPP 4 Government Press Release, Home Office, $17^{\text {th }}$ April 2000.
} 
merger as advantageous if the merged services could operate with greater technical efficiency than the existing services.

The police service is often cited as a classic example of a public good as defined by Samuelson (1956), since it can be argued that it provides a service which is both non-rival in consumption and non-excludable. We use this idea to set up a framework in which the production activity of the police service uses exogenously determined inputs to provide two outputs, at least one of which has the characteristics of a pure public good, and the other output is provided by the public sector without a specific user charge.

The paper is organised as follows. In Section II we discuss the background to in choosing our inputs and output specifications for our model. Section III outlines the model and our interpretation of the non-parametric measurements. We review, in that section, two aspects of the analytical basis; the first is the description of the production set that characterises the technology that we wish to discuss, while the second is the arguments relating to the measurement of the efficiency gains from mergers. Section IV presents our results on the potential efficiency gains from the proposed mergers and we conclude with Section V.

\section{DATA AND MODEL SPECIFICATION FOR MEASURING POLICE FORCE MERGERS.}

The literature on modelling the efficiency of police forces has led economists to posit two alternative methodologies, the cost and the production approach (see Drake and Simper, 2003). The former relates inputs/costs to possible outputs/outcomes (such as offences cleared); see early cost function examples of US policing by Darrough and Heineke (1979), Gyapong and Gyimah-Brempong (1988) and more recently Nyhan and Martin (1999); and for the UK, Cameron (1989), and Drake and Simper (2000). Whereas, the latter production methodology, relates the number of offences committed to the effectiveness of forces in offences cleared; see Thanassoulis (1995) for a UK example, Sun (2002) for a Taiwanese example, and finally Diez-Ticio and 
Mancebon (2000) for an example of the production approach utilised to assess the efficiency of Spanish policing.

There has been a wide range of output measures utilised in measuring police force efficiency. For example, Darrough and Heineke (1979) use 1 input and 6 outputs including 4 clear up rates, crimes against the person and population (to account for the service function of the police); Nyham and Martin (1999) have 2 inputs and 3 outputs that include the number of crimes cleared, response time to 911 calls, and the number of crimes. Finally, in the case of English and Welsh police force analysis, Drake and Simper (2000 and 2001), for example, use 4 inputs but have different outputs. In the former study these include: clear up rates, total traffic offences, and number of breathalyser tests, while in the latter study they use 5 outputs including: \% of time officers spend patrolling the beat; violent crime clear up rate; burglary clear up rate; \% success rate in answering a 999 call within a specified target time limit; and \% of cases in which officers arrive at the scene of the crime within a specified time after a 999 call.

The above studies show that, when modelling police force efficiency, there are a considerable number of outputs that can potentially be included in the cost function specification. These output (outcome) variable choices also depend on whether the investigator is interested in the preventive/proactive or response/reactive nature of policing (for a review of input/output specifications in policing, see Drake and Simper, 2003). Spottiswoode noted the importance of proactive/preventive policing and proposed that any model should take into account all factors of policing. That is, "the selected outcome measures capture the essence of police outcomes and thus, implicitly or explicitly, the many dimensions to policing. The focus of the outcome measures should be on what the police are being expected to achieve for the money they have. This is different from trying to model everything that forces do on a dayto-day basis” (page. 16). Hence, an efficiency model should have its outputs/outcomes based on a set of BVPIs from both the proactive/preventive and response/reactive methodologies.

However, this creates a difficulty in two respects. Firstly, in choosing output variables from the large number (over 250) of Best Value Performance Indicators (BVPIs), Socio-economic, census, and other data sets available. Secondly, in determining the quality of reporting and sampling techniques in the data collection. As the initial 'demonstration project report' (Home Office, 2001, precursor to the 
final Spottiswoode) suggested, a number of criteria were used to assess the appropriateness of the data and they included:

1. Data quality (including robustness and consistency between Police Forces)

2. Consistency with the Government's overall objectives

3. The extent to which it might be manipulated by individual Police Forces.

(Home Office, 2001, page. 19).

As this paper is concerned with the gains to efficiency from X-efficiencies and possible scale-efficiencies the model we follow is the cost approach. We adopt a model of police service activity based on a previous study by Drake and Simper (2005). There are two outputs $\mathbf{y}=\left(y_{1}, y_{2}\right)$ and four inputs $\mathbf{x}=\left(x_{1}, x_{2}, x_{3}, x_{4}\right)$, and data on each is available for 43 police services for each of the years 2000-01, 200102, 2002-03 and 2003-04. The data are from various Home Office reports.

The first output variables reflect success in solving reported crimes $\left(y_{1}\right)$, and is calculated as the 'Number of Crimes Cleared Up'. The number of cleared up crimes is a particularly good variable as it provides a measure of the success of the police in fighting and solving crimes, but also acts as a deterrent in the sense that criminals will assess the probability of being prosecuted ahead of committing a crime. This so called response/reactive methodology of measuring policing can be found in a number of studies, including Todd and Ramanathan (1994), and Byrne et al (1996) who argue that, even though half of the police's community work cannot be modelled, a production function can still be estimated. They break down police activities in crime prevention "where the crime is contemplated but not committed," and crime repression, where the "crime has occurred," and use an argument from Schmidt and Witte (1984) that any criminal is likely to assess the probability of getting caught after committing a crime. It is argued that the probability of arrest is linked to the number of arrests in a police force, and in particular to the number of convictions.

The second output variable is the 'Index of Days of Police and Civilian Support Person Availability', measured as a variable translation: [2×(max of sample days lost to sickness) - days lost to sickness]. With respect to output (outcome) 2, this corresponds closely with any of the key aims and objectives in policing. Hence, it would clearly be desirable to reduce the incidence of sickness absence in police forces as it may well be that days lost are actually a symptom of underlying morale or 
management problems, and may therefore be related to poor performance in other key output (outcome) areas. In this paper we argue that output $y_{2}$ has the characteristic of a public good since it represents the availability of a protective police service to meet public needs.

The input variables reflect the real resources available to the police and the number of crimes that require clear-up and follow previous 'cost' studies including Nyhan and Martin (1999) and Drake and Simper (2000). These are measured as:

$x_{1}=$ Total Net Budget in constant (2002) prices; the deflator is the UK GDP implicit deflator for gross value added at basic prices published by the Office of National Statistics

$x_{2}=$ Total Number of Violent Crimes

$x_{3}=$ Total Number of Material Crimes

$x_{4}=$ Other Recorded Crimes

These inputs are treated as outside the control of each police service and so are assumed not to enter its decision making possibilities. Budgets are set by central Government, and recorded crimes are a reflection of the environment in which each service operates. The choices of each service are to devote the exogenously determined resources to clearing up crime and to providing a general service availability to the public - as in the lighthouse analogy from the theory of public good provision.

An issue that has arisen in precious work in this area is whether police services in London (London Metropolitan, and London City) should be treated as outliers, since their operating characteristics and relative size make them exceptional within the context of England and Wales. We compute all of our merger efficiency evaluations for two samples, with and without London Metropolitan, and London City, respectively comprising 43 and 41 police services. The choice of benchmark sample is contingent also on the assumption that each service faces the same output valuation or imputed prices.

TABLE 1 HERE

FIGURE 1 HERE 
The proposed mergers are summarised in Table 1 and forces in England and Wales are presented in Figure 1, the mergers have been taken from the UK Government's letter to Chief Constables published in December 2005. These have clearly been chosen to be geographically adjacent, and we distinguish different police services by region. The number of mergers proposed differs amongst regions, with a single merged police service proposed for Wales, but up to six different mergers proposed for the South East. There are 28 proposed mergers in all.

In computing the linear programmes we expressed all data in terms of ratios of the sample mean for each variable for each year ${ }^{5}$. This has the advantage of removing major differences in the absolute size of the dimensions and units of the variables. The availability of a panel of data allows us to improve the interpretation of the results in two ways. First we are able to compare the consistency of the findings about merger efficiency across different years in a period during which the police service was undergoing major challenges. Secondly, we are able to apply the suggestion of Ruggiero (2004) that using data on inputs and outputs that have been averaged over a number of periods reduces the problem of measurement error. Consequently we use five datasets on which to evaluate the mergers: each of the years 2001-04 separately, and the average of the years 2001-04. The next Section presents the merger model to be estimated.

\section{THE DEA MODEL OF THE GAINS FROM MERGERS OF PRODUCTION UNITS}

The analysis of merger potential usually exploits the idea of sub-additivity of the cost functions of producers. In considering the police service, we argue that a production model that incorporates the choice of the level of public goods that can be provided by exogenous inputs is appropriate. This requires a re-formulation of the cost subadditivity test to present an output orientation. We begin by setting out the

\footnotetext{
5 All of the linear programmes for the data envelopment analysis and the merger evaluations were written by the authors in GAMS (General Algebraic Modelling System) software.
} 
assumptions about the relevant technology. We define a production set describing how l outputs, $\mathbf{y} \in \mathrm{R}_{+}^{l}$, are made by $m$ inputs $\boldsymbol{x} \in R_{+}^{m}$

$$
T(x, y)=\{(x, y): x \text { can make } y\}
$$

From this we can define an equivalent representation of the technology, the output possibility set $P(\boldsymbol{x})$ :

$$
P(\boldsymbol{x})=\{\boldsymbol{y}: \boldsymbol{y} \in T(\boldsymbol{x}, \boldsymbol{y}) \text { for given } \boldsymbol{x}\}
$$

We shall assume throughout the paper that these representations of the technology have the properties of convexity and free disposability. These assumptions ensure that convex combinations of feasible inputs-output baskets are also feasible, and that inputs are not congested in the sense that using more of one input requires use of more of the other inputs, and that none of the outputs is undesirable. Assumptions concerning returns to scale of the technology are critical for the analysis of mergers and are considered in more detail below.

We adapt the standard theory of the firm producing private outputs to develop an output valuation function. This is the public service counterpart to the private firm's revenue function, and it is defined as follows. Given a set of exogenous output valuations, that is, the government's imputed shadow prices of public service outputs, $\mathbf{p}$, the output valuation function is the maximum value of technically feasible outputs when inputs are given exogenously.

$$
W(\mathbf{x}, \mathbf{p})=\max _{\mathbf{y}}\left\{\mathbf{p}^{\prime} \mathbf{y}: \mathbf{y} \in P(\mathbf{x})\right\}
$$

In examining police services in the UK we observe that the assumption that inputs are exogenous is indeed plausible. The outputs include services which have the characteristics of public goods and are provided at a level which reflects the efficient choices of each police service. Consequently a valuation of output maximisation model is the most sensible representation. The output valuations are not market prices but the Government's chosen valuations of the public good outputs of the police 
services, and consequently are exogenous to each police service, and can be assumed to be identical over all regions of the country.

Output Valuation super-additivity will (weakly) justify a merger if the merged valuation is not less than the aggregate individual valuations. For example, in the case of two producers, $a$ and $b$, a merger is justified if:

$$
W\left(\mathbf{x}^{a}+\mathbf{x}^{b}, \mathbf{p}\right) \geq W\left(\mathbf{x}^{a}, \mathbf{p}\right)+W\left(\mathbf{x}^{b}, \mathbf{p}\right)
$$

By duality, this is equivalent to super-additivity of the output possibility sets ${ }^{6}$ :

$$
P\left(\mathbf{x}^{a}\right)+P\left(\mathbf{x}^{b}\right) \subseteq P\left(\mathbf{x}^{a}+\mathbf{x}^{b}\right)
$$

The Bogetoft and Wang (2005) model used in this paper evaluates mergers by calibrating the super-additivity of the piecewise linear representations of the output possibility sets with and without mergers. This allows us to evaluate mergers without requiring output price or valuation data. We are assuming in effect that all the service providers face the same output prices or valuations at any given time. This makes sense in a public good model of a democracy with regional jurisdictions such as the UK. The assumption states that the Government's implicit valuation of police service outputs is the same for all citizens wherever they live. It would be defensible to extend this constancy over short periods of time in order to use a panel data set; however the way in which we shall use our data panel in this paper does not explicitly require this extended assumption of the constancy of output valuations over time.

We investigate a merger as a collection of firms for which the inputs and outputs have been combined. Assume that $J$ of the $N$ police forces are merged, and arbitrarily re-labelled $k=1 \ldots J$ within the merged group. A merged group, that is, what Färe et al (1994) call an out of sample or hypothetical firm, has inputs and outputs that are the summations of the inputs and outputs of the merged firms:

$$
\tilde{x}_{i}^{J}=\sum_{k=1}^{k=J} x_{i k}, \quad i=1 \ldots m
$$

\footnotetext{
6 The output possibility set is super-addititive because it is a "less than" set bounded above by the production possibility frontier, see Färe, Grosskopf and Lovell (1994, p.38).
} 


$$
\tilde{y}_{r}^{J}=\sum_{k=1}^{k=J} y_{r k}, \quad r=1 \ldots l
$$

The objective is to compute measures of Overall Merger Efficiency, $F^{J}$, and to decompose this into constituent components. First, we calculate an outputorientated radial measure of overall merger efficiency, $F^{J}$, to evaluate the relative efficiency of a proposed merger of $J$ forces, subject to constraints which define a piecewise linear representation of the output possibility set. A piecewise linear representation of the output possibility set is based on observations of the input and output vectors of the $N$ forces, collected in the matrices: $\mathbf{X}$ and $\mathbf{Y}$, and a set of nonnegative intensity weights, $\lambda$ :

$$
P^{P L R}(\mathbf{x})=\{\mathbf{y}: \mathbf{X} \lambda \leq \mathbf{x}, \mathbf{Y} \lambda \geq \mathbf{y}, \lambda \geq \mathbf{0}, \text { for given } \mathbf{x}\}
$$

Subsequently we make use of the vectors: $\mathbf{s}^{-}, \mathbf{s}^{+}$to represent the input and output slack variables respectively in [8].

The overall evaluation of merger efficiency uses the aggregated inputs and outputs from [6] and [7] in the model:

$$
\begin{aligned}
& \max F^{J} \quad \text { s.t. } \\
& \sum_{j=1}^{j=N} \lambda_{j} x_{i j} \leq \tilde{x}_{i}^{J}, i=1 \ldots m \\
& \sum_{j=1}^{j=N} \lambda_{j} y_{r j} \geq F^{J} \tilde{y}_{r}^{J}, r=1 \ldots l \\
& \lambda_{j} \geq 0
\end{aligned}
$$

This suggests the merger is advantageous if $F^{J}>1$, i.e. the merged group could produce greater aggregate outputs with the same input usage, and it is not advantageous if $F^{J} \leq 1$.

The key to understanding the model's results is that we measure the potential for efficiency gains. This means that to achieve the gains which the model demonstrates are possible, appropriate incentive mechanisms must be in place. The model does not state that the gains will be achieved by the indicated merger. It states 
only that there is a potential gain to the merger arising from the measured inefficiency of the aggregated forces. If no such inefficiency exists either because the forces are already efficient, or because the merger group is infeasibly large for the reference technology, then the merger is not advantageous. If inefficiency of the feasible merged group is observed, relative to the chosen reference technology, then the merger may be beneficial if it is accompanied by incentives designed to capture the efficiency gains. In the absence of the relevant incentives, the merger will presumably fail to achieve its potential. The test embodied in the model tells the investigator whether there could be a positive return to better incentive design within a merged group of forces.

The specification of returns to scale of the reference technology is important in the evaluation of the merger possibilities because by definition a merged group of forces is a rescaling of the individual forces in the group. For constant returns to scale, $C R S$, the piecewise linear representation requires that intensity weights are nonnegative: $\lambda_{j} \geq 0, j=1 \ldots N$. For variable returns to scale, $V R S$, the requirement is $\lambda_{j} \geq 0, j=1 \ldots N$, and $\sum_{j=1}^{j=N} \lambda_{j}=1$. These technologies are nested, with the VRS reference technology being a subset of the CRS reference technology ${ }^{7}$.

Bogetoft and Wang (2005, proposition 1) demonstrate that a CRS reference technology has the necessary and sufficient conditions to ensure that $F^{J} \geq 1$ for arbitrary mergers. However for a VRS reference technology, these conditions may not hold and it is possible that there will fail to be a feasible solution to the linear programme defined by [9]. That would not of course imply that the merger itself was infeasible in a practical sense. Infeasibility of the non-parametric programme [9] would signify that the merged output vector was too large to be feasible relative to the chosen reference technology, or that the merged inputs vector could not be made available by combining the observed inputs in a feasible way relative to the chosen reference technology, that is, by non-negative intensity weights which summed to unity.

In this paper we are investigating a set of hypothetical mergers comprising a wide range of different forces. Consequently we can think of the range of potential mergers as comprising a blue-print for the organisational structure of the police

\footnotetext{
${ }^{7}$ The CRS reference technology is a convex cone containing the observed points in input-output space, while the VRS reference technology is the convex hull of the observed points.
} 
service. In principle any subset of the potential mergers may be evaluated as a potential candidate for implementation, and the implementation has the characteristics of a long run decision with no pre-determined factors. This strongly suggests that for overall merger efficiency measurement, the CRS reference technology is the appropriate benchmark. This is the one on which we focus for overall merger efficiency, although we do calculate the VRS case to check for programme infeasibility.

Bogetoft and Wang (2005) suggest a decomposition of the overall merger efficiency into three components, the individual technical efficiency effect, $T^{J}$, a harmony, scope or mixture effect, $H^{J}$, and a scaling or size effect, $S^{J}$. The decomposition is multiplicative:

$$
F^{J}=T^{J} \times H^{J} \times S^{J}
$$

The individual technical efficiency effect adjusts the merged outputs for potential efficiency gains within the group as each member is given incentives to reach the frontier for the group. In this paper we compute the individual technical efficiency effect model for the VRS case. Our argument is that, unlike the situation when we are contemplating the range of potential mergers which is analogous to a long-run blueprint for the police service, within each actual merger there will be short-run difficulties and adjustments in forging a united group. The preferences and customs of the individual agents amongst other factors will add to this difficulty, and consequently it is more appropriate to adopt a less flexible reference technology when computing the within merger efficiency-adjusted outputs. Consequently, the individual technical efficiency effects index is a radial measure of the component of overall merger efficiency which can be attributed to the effect on each of the members of the merged group of achieving the frontier efficiency of the group ${ }^{8}$.

The second component of the decomposition identified by Bogetoft and Wang (2005) is a form of economies of scope effect. However this does not arise from the merger of forces with different output portfolios in the textbook sense of economies of scope, but rather from the merger of different output mixes from a given set of inputs. The merged group can adopt an output mix which is intermediate amongst the

\footnotetext{
${ }^{8}$ Each of the models for the component effects is shown in the appendix.
} 
different output mixes of the individual members. In effect it is exploiting the concavity of the piecewise linear representation of the production possibility frontier of the output possibility set. Using the indicator $H^{J}$ to measure the mixture effect, values of the indicator $H^{J}>1$ state that harmonising the output mix within the merged groups will improve efficient merger performance, and values $H^{J}<1$ state that the problem of harmonising very different output mixes will detract from merger performance. Bogetoft and Wang (2005) argue that any remaining efficiency gains must be due to scale efficiency. This reflects the fact that the merged group will be able to take advantage of its size relative to other producers to exploit any remaining returns to scale. This effect may be opposite to the other efficiency gains if the police service generally is subject to decreasing returns to scale, signalled for example by the component forces each having decreasing returns to scale. The scale effect is computed as a residual after adjusting merged outputs for technical efficiency and scope or harmony effects.

Care needs to be exercised in distinguishing these components of the decomposition of overall merger efficiency since each follows in a sequence of prior adjustments to the out-of-sample data representing the merged group. The next Section discusses our findings on efficiency in merging English and Welsh police forces.

\section{RESULTS}

Although we have computed results for both samples with and without London, we concentrate here on the results for the sample without the police services in London. We begin in Table 2 with a benchmark analysis of the whole sample of 41 police forces in order to indicate the relative performance of each of the different police forces. This is reported for the average of the panel samples over the period 2001-04, and indicates which police forces are the efficient peers of the others, and the inputs and outputs which are given the positive weight in determining the relative outputorientated efficiency of each force. The dual to each envelopment model is a multiplier model with dual variables which are the components of the marginal rates of substitution and transformation between inputs and outputs. By the complementary 
slackness theorem of linear programming, we know that positive slacks in the envelopment input and output constraints are associated with zero values for the corresponding input and output multiplier weights in the dual to the DEA programme:

$$
\begin{aligned}
& u_{r} s_{r}^{+}=0, r=1 \ldots l \\
& v_{i} s_{i}^{-}=0, i=1 \ldots m
\end{aligned}
$$

Consequently, we can identify positive multiplier weights with input and output dimensions in which each police force is fully constrained, and therefore we can identify the absent inputs and outputs as ones where the police force has positive slack. In Table 2, we further identify the returns to scale region in which each police force operates and the measure of its scale efficiency.

\section{TABLE 2 HERE}

The average inefficiency of police forces is 24.5 percent relative to the $C R S$ reference technology and fully 24 percent of this is due to scale inefficiency. Of the sample of 41 services, 35 are operating with decreasing returns to scale, and this suggests that the potential for large efficiency gains due to mergers is limited, at least when using the inputs and outputs employed in this model. Three forces act as peers for all of the others, Durham, Greater Manchester and Lincolnshire.

It is clear that scale efficiency in these data will not able to contribute strongly to forming a case for mergers in the context of this crime clear-up model of police activity. Among the reasons for this is the clustering of the majority of police forces in the DRS space of the reference technology. This may arise if one or two police forces are acting as super-efficient outliers whose CRS performance pulls the frontier away from the majority of other police services. One possible reason for this is that since crime may be concentrated in major cities, police forces with large city jurisdiction may exhibit different efficiency characteristics than others. We performed an Andersen-Petersen (1993) super-efficiency analysis to determine whether this was the case. The super-efficient police forces are then ranked by the size of multiplicative factor which can either expand the inputs without removing that service from the efficient production frontier, or contract the outputs without 
removing that force from the efficient production frontier. Andersen-Petersen (1993) super-efficiency results for the pooled average sample are given in Table 3. The results indicate that Lincolnshire (15) is an extreme outlier whose presence is strongly distorting the efficiency results. This is a surprising result because Lincolnshire does not contain a major city of the scale of Manchester or Birmingham; nevertheless it is clearly a distorting outlier.

\section{TABLE 3 HERE}

As a consequence, we re-computed the overall DEA efficiency scores, and the merger efficiency gains, for a sample excluding Lincolnshire. The finding of prevalent decreasing returns to scale is confirmed again, but this time there are no extreme outliers amongst the list of efficient forces, which comprise: Durham (2), Cleveland (3), Greater Manchester (6), Warwickshire (21), Devon \& Cornwall (35) and Hampshire (39). It appears therefore that in this public good model of the police service, where the discretionary outputs are crime clear-up and service availability, size does not confer efficiency advantages. Larger police forces, that is, those with larger budgets and greater recorded crime levels, do not demonstrate an ability to achieve greater clear-up rates relative to recorded crime. This is confirmed in Figure 2 where we plot the normalised average crime clear-up rate against police force budgets as the input scale variable. Lincolnshire is excluded from Figure 2. The two dominant forces are Durham and Greater Manchester, and, of these, Durham has an average budget level substantially less than the median value for the other forces. Durham's small scale but high clear-up is instrumental in pushing many services into the decreasing returns to scale area of input-output space.

Although Figure 2 does not represent exactly the multi-variable model we have used, we can represent several ideas on this figure. We superimpose, for example two different convex cones enveloping the data and labelled CRS1 (includes Durham) and CRS2 (excludes Durham). These give an approximate indication of the incidence of the CRS reference technologies. We also superimpose two different convex hulls enveloping the data and labelled VRS1 (includes Greater Manchester) and VRS2 (excludes Greater Manchester). The broken line labelled AA' is of interest because under an output-oriented data envelopment analysis model, points to the right of this line will be categorised as decreasing returns to scale, whereas in an input 
orientation these points would be categorised as increasing returns to scale. This ambiguity arises because these points are so far from the frontier that either smaller input scale with constant output or larger output scale with constant input will improve their efficiency ${ }^{9}$.

\section{FIGURE 2 HERE}

We turn now to investigate the efficiency gains of the proposed mergers and their decomposition into technical efficiency effects, scope (or mixture) effects, and scale effects. We report each of these with respect to the CRS reference technology since we argued that they represent a possible blue-print of the organisational structure and therefore can be regarded as a range of possible long run decisions. Within each merged group however we adjust the members' efficient input levels with reference to the VRS reference technology of the group, since we anticipate that any one particular merger must be subject to short run costs of adjustment. Clearly other approaches are possible, and we have investigated these as well, as we report subsequently. In Table 4 we report the merger efficiency gains derived from the averaging of the individual samples over the period 2001-04. We have excluded the extreme outlier Lincolnshire from the reference technology, and consequently not computed merger efficiency gains where the proposed merger includes Lincolnshire.

\section{TABLE 4 HERE}

To read Table 4, it is important to reflect on what has been measured. The merged forces have been constructed simply by summing the inputs and outputs of the component forces. The resulting summation of forces could potentially lie on the or below the efficient frontier constructed from all of the existing forces. If it lies below the efficient frontier, $\left(F^{J}>1\right)$, then the merged force offers the potential to improve efficiency by an expansion of outputs equivalent to $\left[100 \times\left(F^{J}-1\right)\right] \%$. Alternatively, it might be argued that, for given crime incidence and reporting, the same level of service that exists in the current forces could be provided at a saving in police budgets of $\left[100 \times\left(F^{J}-1\right)\right] \%$. The assumption underlying this is that the relevant

\footnotetext{
${ }^{9}$ For discussion of this ambiguity see Färe et al (1994, pp 122-4).
} 
incentive mechanisms are in place after merger to achieve the potential efficiency gains. The analysis shows only how far a simple summation of two or more forces lies from the efficient frontier. it does not imply that the potential efficiency improvements will automatically follow from the merger. Indeed the hidden adjustment costs may be sufficiently large to prevent the potential gains from being achieved. That is why it is important to reflect that this is not a cost-benefit analysis. It displays what could be theoretically possible before adjustment costs are taken into account, not what will happen in practice when adjustment costs actually occur.

Technical efficiency improvements are indicated in 11 of the proposed mergers covering a range of $2-10 \%$ efficiency improvements. This may underestimate the long-run technical efficiency gains that are available because we compared this to a relatively conservative close envelopment frontier assuming variable returns to scale at the group level. Nevertheless, assuming that the crime clear up rate remained constant, this technical efficiency improvement could translate as the equivalent increase in the public good measured as availability of the police service, and would be equivalent to a $2-10 \%$ reduction in days lost due to sickness. The results indicate that the major efficiency gains arise because of the substantial variability in the supply of the public good form of output. When two forces are merged the analysis seeks the efficiency gain that comes from combining the best output achievements of the merged group relative to the national picture. The assumption is that when two or more forces merge, the availability of the public good in the best of them becomes a potential target for every member of the group. As an example consider the simple merger of forces 7 and 8: Merseyside and Cheshire (merger number 5, Table 1). The indication is that there is a potential for over $60 \%$ improvement in efficiency. This does not arise from size since both forces exhibit decreasing returns to scale, and only $2 \%$ of the gain is associated with each improving its pure technical efficiency. The bulk of the gain arises from provision of the public good: availability of service. Looking at the individual results for these two forces in table 2, we see immediately that while Cheshire registers availability of service (output 2) as a positively weighted output in its efficiency score, Merseyside does not. The merged force shows a potential efficiency improvement of over $60 \%$ because the analysis assumes that Merseyside can aspire to supply the level of police force availability that Cheshire already supplies. There may be cogent reasons to doubt this 
will occur. The importance of the exercise is to show what might be possible, and from what sources it might arise.

More broadly, the lesson of these data is that some forces are able to offer far greater availability of police service cover than others with similar budgets and clear up rates and crimes reported. The reasons for this are clearly an important topic for further research. They may be related to the nature of city versus rural policing, or to the range of socio-income grouping in different jurisdictions. As usual with data envelopment analysis, we do not learn the answers, but we do learn what questions to ask.

We already noted the prevalence of decreasing returns to scale in this public good production model of the police service. This could be expected to undermine the case for mergers, and it is indeed clear that the size or scale index indicates that in every case there is no advantageous merger on this criterion alone. However all of the proposed mergers are advantageous when other effects are added in.

The major improvement from the mergers comes about through the scope or mixture effect in this police force model. As table 2 indicated, only a minority of forces make use of the second, public good, output, representing the availability of police service, in computing their maximal efficiency. The mergers allow the merged groups to take full advantage of the concavity of the frontier of the piecewise linear representation of the output possibility set to find combinations of the two outputs which are more efficient than the individual levels of provision.

The other aspect of merger not investigated here is operational efficiency in terms of costs and expenditures. This may offer conflicting results. However, by adopting a public good model of the police service we have shown that mergers allow the forces to offer a more efficient range of outputs than is currently the case. These gains are independent of the size of the merged groups and the nature of this model of the police service indicates that size itself offers no potential efficiency gains.

\section{CONCLUSIONS.}

This paper is the first to utilise a new non-parametric techniques, proposed by Bogetoft and Wang (2005), to analyse English and Welsh police force mergers. In line with previous studies in policing, we estimate a model that includes costs, but 
also a public good, 'number of days worked' relative to sickness days. As discussed, the police service is often cited as a classic example of a public good, since it can be argued that it provides a service which is both non-rival in consumption and nonexcludable. We used this idea to set up a framework in which the production activity of the police service uses exogenously determined inputs to provide two outputs, at least one of which has the characteristics of a pure public good, and the other output is provided by the public sector without a specific user charge.

Furthermore, the results obtained provide some important insights not only in terms of the relative efficiency of police forces, but also in respect of where the efficiencies from merging forces might come from. We find that there are possible efficiency savings associated with staff resources between 10 and 70\% after merging forces in line with the Home Secretary's guidelines. That is, some forces are able to offer far greater availability of police service cover than others with similar budgets and clear up rates and crimes reported. Merging forces would therefore allow a greater pool of talent within the new force and would increase the economic good associated with policing in England and Wales. 


\section{REFERENCES:}

Andersen, P., and Petersen, N.C. (1993), “A Procedure for Ranking Efficient Units in DEA,” Management Science, 39, 1261-1264.

Bogetoft, Peter., and Dexiang, Wang. (2005), "Estimating the Potential Gains from Mergers,” Journal of Productivity Analysis, 23, 145-171..

Byrne, D., Dezhbakhsh, H., and King, R. (1996), “Unions and Police Productivity: An Econometric Investigation,” Industrial Relations, 35, 566-584.

Cameron, S. (1989), "Police Cost Function Estimates for England and Wales," Applied Economics, 21, 1279-1289.

Darrough, M. N., and Heineke, J. M. (1979), "Law Enforcement Agencies as Multiproduct Firms: An Econometric Investigation of Production Cost.” Public Finance 34, 176-195.

Department of the Environment, Transport and the Regions (DETR). (1999), Performance Indicators for 2000/2001, Her Majesty’s Stationary Office, London, UK.

Diez-Ticio, A., and Mancebon, M-J. (2002), “The Efficiency of the Spanish Police Service: An Application of the Multiactivity DEA Model.” Applied Economics, 34, 351-362.

Drake, L. M., and Simper, R. (2005), “The Measurement of Police Force Efficiency: An Assessment of UK Home Office Policy,” Contemporary Economic Policy, 23, 465-482.

Drake, L. M., and Simper, R. (2003), “The Measurement of English and Welsh Police Force Efficiency: A Comparison of Distance Function Models,” European Journal of Operational Research, 147, 165-186.

Drake, L., Simper, R., (2001), “The Economic Evaluation of Policing Activity: An Application of a Hybrid Methodology,” European Journal of Law and Economics. 12, 181-200.

Drake, L. M., and Simper, R., (2000), "Productivity Estimation and the SizeEfficiency Relationship in English and Welsh Police Forces: An Application of DEA and Multiple Discriminant Analysis.” International Review of Law and Economics, 20., 53-73.

Färe, R, Grosskopf. S., and Lovell. C.A.K. (1994), Production Frontiers, Cambridge, Cambridge University Press. 
Her Majesties Inspectorate of Constabulary (HMIC). (1998), What Price Policing, Her Majesties Stationary Office, London, UK.

Home Office. (2001), Police Efficiency Demonstration Project, Her Majesties Stationary Office London. UK.

Gyapong, A. O., and Gyimah-Brempong, K. (1988), "Factor Substitution, Price Elasticity of Factor Demand and Returns to Scale in Police Production: Evidence from Michigan,” The Economic Journal, 54, 863-878.

Nyhan, R. C., and Martin, L. M. (1999), “Assessing the Performance of Municipal Police Service Using Data Envelopment Analysis: An Exploratory Study,” State and Local Government Review, 31, 18-30.

O.Conner, D. (2005), Closing the Gap, HM Inspectorate of Constabulary, Home Office, London, UK.

Ruggiero, J. (2004), “Data Envelopment Analysis with Stochastic Data,” Journal of the Operational Research Society, 55, 1008-1012.

Samuelson, P. (1956), "The Pure Theory of Public Expenditure," Review of Economics and Statistics, 36, 387-389.

Stephens, M. (1994), “Care and Control: The Future of British Policing,” Policing and Society, 4, 237-251.

Sullivan, R. R. (1998), “The Politics of British Policing in the Thatcher/Major State,” The Howard Journal, 37, 306-318.

Spottiswoode, (2000), Improving Police Performance. Public Services Productivity Panel, H. M. Treasury, London, UK.

Sun, S. (2002), "Measuring the Relative Efficiency of Police Precincts using Data Envelopment Analysis,” Socio-Economic Planning Sciences, 36, 51-71.

Thanassoulis, E. (1995), “Assessing Police Forces in England and Wales using Data Envelopment Analysis,” European Journal of Operational Research 87, 641657.

Todd, R., and Ramanathan, K.V. (1994), "Perceived Social Needs, Outcomes, Measurements, and Budgetary Responsiveness in a Not-for-Profit Setting; Some Empirical Evidence,” The Accounting Review, 69, 122-137. 


\section{APPENDIX: models for the decomposition of potential merger gains}

The individual technical efficiency effect applies to the units within the merged group

$$
\begin{aligned}
& \max F^{o} \quad \text { s.t. } \\
& \sum_{k=1}^{k=J} \lambda_{k} x_{i k} \leq x_{i o}, i=1 \ldots m, o=1, \ldots J \\
& \sum_{k=1}^{k=J} \lambda_{k} y_{r k} \geq F^{o} y_{r o}, r=1 \ldots l \\
& \lambda_{k} \geq 0 ; \sum_{k=1}^{k=J} \lambda_{k}=1
\end{aligned}
$$

This provides a new set of merged group outputs after the efficiency adjustment:

$$
\begin{aligned}
& E \tilde{y}_{r}^{J}=\sum_{k=1}^{k=J} F^{k} y_{r k}, r=1 \ldots l \\
& \Rightarrow E \tilde{y}_{r}^{J} \geq \tilde{y}_{r}^{J}, r=1 \ldots l
\end{aligned}
$$

Using these within-merger efficiency-adjusted outputs, re-compute the overall model:

$$
\begin{aligned}
& \max F^{* J} \quad \text { s.t. } \\
& \sum_{j=1}^{j=N} \lambda_{j} x_{i j} \leq\left(\tilde{x}_{i}^{J}\right), i=1 \ldots m \\
& \sum_{j=1}^{j=N} \lambda_{j} y_{r j} \geq F^{* J}\left(E \tilde{y}_{r}^{J}\right), r=1 \ldots l \\
& \lambda_{j} \geq 0
\end{aligned}
$$

The first element in the decomposition is: $T^{J}=F^{J} / F^{*}$. The purpose of the harmony, scope or mixture effect, $H^{J}$, is to calculate by how much the average output of the merged group could have been expanded by use of the average input. The required programme is:

$$
\begin{aligned}
& \max H^{J} \quad \text { s.t. } \\
& \sum_{j=1}^{j=N} \lambda_{j} x_{i j} \leq\left[\left(\tilde{x}_{i}^{J}\right) / J\right] \quad i=1 \ldots m \\
& \sum_{j=1}^{j=N} \lambda_{j} y_{r j} \geq H^{J}\left[E \tilde{y}_{r}^{J} / J\right] \quad r=1 \ldots l \\
& \lambda_{j} \geq 0
\end{aligned}
$$

Finally, the scaling or size effect, $S^{J}$ is a residual calculated by the model:

$$
\begin{aligned}
& \max ^{J} \quad \text { s.t. } \\
& \sum_{j=1}^{j=N} \lambda_{j} x_{i j} \leq\left(\tilde{x}_{i}^{J}\right), i=1 \ldots m \\
& \sum_{j=1}^{j=N} \lambda_{j} y_{r j} \geq S^{J}\left[H^{J} E \tilde{y}_{r}^{J}\right], r=1 \ldots l \\
& \lambda_{j} \geq 0
\end{aligned}
$$




\section{FIGURE 1 \\ GEOGRAPHICAL ENGLISH AND WELSH POLICE SERVICE BOUNDARIES}

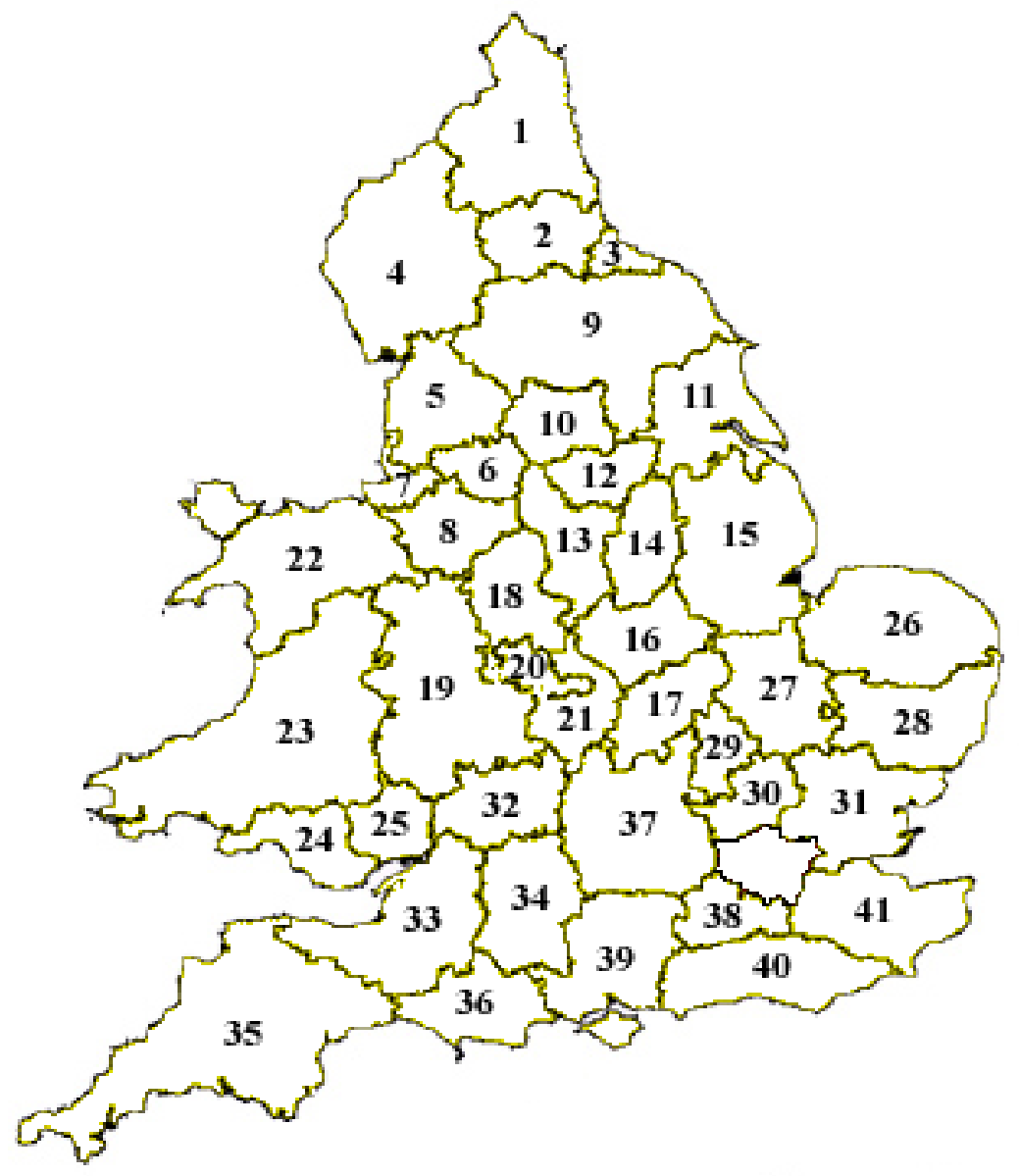
1. Northumbria
11. Humberside
21. Warwickshire
31. Essex
2. Durham
12. S. Yorkshire
22. North Wales
32. Gloucestershire
3. Cleveland
13. Derbyshire
23. Dyfed Powys
33. Avon \& Somerset
4. Cumbria
14. Nottinghamshire
24. Gwent
34. Wiltshire
5. Lancashire
15. Lincolnshire
25. South Wales
35. Devon \& Cornwell
6. G. Manchester
26. Norfolk
36. Dorset
7. Merseyside
17. Northamptonshiry
27. .
36. Dorset
8. Cheshire
18. Staffordshire
28. Suffolk
29. Bedfordshire
38. Surrey
9. N. Yorkshire
19. West Mercia
30. Hertfordshire
39. Hampshire
40. Sussex
41. Kent

n.b. blank geographic area denotes City of London and Metropolitan forces which are excluded in our analysis. 
FIGURE 2

NORMALISED CRIME CLEAR-UP AND POLICE SERVICE BUDGET

average clear-up rate v. service budget, 2001-04

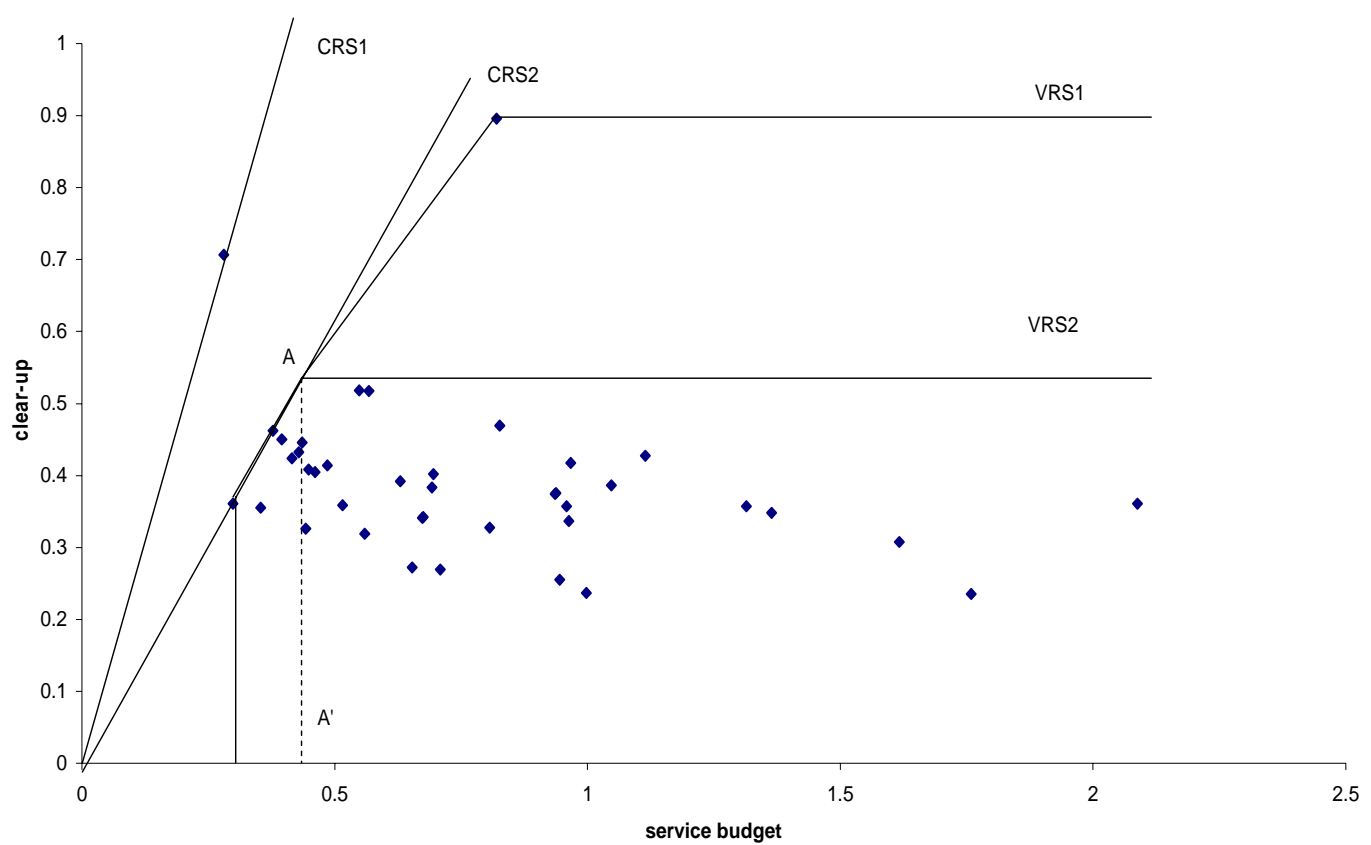


TABLE 1

PROPOSED MERGERS OF 41 POLICE SERVICES BY REGION

\begin{tabular}{|c|c|c|}
\hline North East & North West & Yorkshire \& Humberside \\
\hline 1 Northumbria & 4 Cumbria & 9 North Yorkshire \\
\hline 2 Durham & 5 Lancashire & 10 West Yorkshire \\
\hline \multirow[t]{4}{*}{3 Cleveland } & 6 Greater & 11 Humberside \\
\hline & Manchester & \\
\hline & 7 Merseyside & 12 South Yorkshire \\
\hline & 8 Cheshire & \\
\hline \multicolumn{3}{|l|}{ potential mergers } \\
\hline $\mathrm{m} 1=1+2+3$ & $\mathrm{~m} 1=4+5$ & $\mathrm{~m} 1=9+10+11+12$ \\
\hline & $\mathrm{m} 2=7+8$ & $\mathrm{~m} 2=9+10$ \\
\hline & $\mathrm{m} 3=4+5+7$ & $\mathrm{~m} 3=11+12$ \\
\hline & $\mathrm{m} 4=6+8$ & \\
\hline East Midlands & West Midlands & Wales \\
\hline 13 Derbyshire & 18 Staffordshire & 22 North Wales \\
\hline 14 Nottinghamshire & 19 West Mercia & 23 Dyfed-Powys \\
\hline 15 Lincolnshire & 20 West Midlands & 24 Gwent \\
\hline 16 Leicestershire & 21 Warwickshire & 25 South Wales \\
\hline \\
\hline \multirow{2}{*}{\multicolumn{3}{|c|}{$\begin{array}{l}\text { potential mergers } \\
\mathrm{m} 1=13+14+15+16+17\end{array}$}} \\
\hline & & \\
\hline $\mathrm{m} 2=13+14$ & $\mathrm{~m} 1=18+19+20+21$ & $\mathrm{~m} 1=22+23+24+25$ \\
\hline \multirow[t]{2}{*}{$\mathrm{m} 3=15+16+17$} & $\mathrm{~m} 2=18+19$ & \\
\hline & $m 3=20+21$ & \\
\hline Eastern & South West & South East \\
\hline 26 Norfolk & 32 Gloucestershire & 37 Thames Valley \\
\hline 27 Cambridgeshire & $\begin{array}{l}33 \text { Avon \& } \\
\text { Somerset }\end{array}$ & 38 Surrey \\
\hline 28 Suffolk & 34 Wiltshire & 39 Hampshire \\
\hline 29 Bedfordshire & $\begin{array}{l}35 \text { Devon \& } \\
\text { Cornwall }\end{array}$ & 40 Sussex \\
\hline $\begin{array}{l}30 \text { Hertfordshire } \\
31 \text { Essex } \\
\text { potential mergers }\end{array}$ & 36 Dorset & 41 Kent \\
\hline $\mathrm{m} 1$ & $\mathrm{~m} 1$ & $\mathrm{~m} 1=38+40+41$ \\
\hline$=26+27+28+29+30+31$ & $=32+33+34+35+36$ & \\
\hline $\mathrm{m} 2=29+30+31$ & $\mathrm{~m} 2=32+33+34+36$ & $\mathrm{~m} 2=37+39$ \\
\hline$m 3=26+27+28$ & & $\mathrm{~m} 3=38+39+40$ \\
\hline $\mathrm{m} 4=27+29+30$ & & $\mathrm{~m} 4=40+41$ \\
\hline $\mathrm{m} 5=26+28+31$ & & $\mathrm{~m} 5=38+39$ \\
\hline & & $\mathrm{m} 6=38+40$ \\
\hline
\end{tabular}


TABLE 2.

DEA RESULTS FROM SAMPLE OF 41 POLICE SERVICES AVERAGED OVER 2001-04

\begin{tabular}{|c|c|c|c|c|c|c|c|}
\hline number & name & $\begin{array}{c}\text { CRS } \\
\text { efficiency }\end{array}$ & peers & $\begin{array}{c}\text { positive } \\
\text { input } \\
\text { weights }\end{array}$ & $\begin{array}{c}\text { positive } \\
\text { output } \\
\text { weights }\end{array}$ & RTS & $\begin{array}{l}\text { scale } \\
\text { eff }\end{array}$ \\
\hline 1 & Northumbria & 0.753 & 6 & 1 & 1 & decreasing & 0.753 \\
\hline 2 & Durham & 1.000 & 2 & 1 & 1 & constant & 1.000 \\
\hline 3 & Cleveland & 0.816 & $2,6,15$ & 1,2 & 1,2 & decreasing & 0.820 \\
\hline 4 & Cumbria & 0.682 & 2,6 & 1 & 1,2 & decreasing & 0.689 \\
\hline 5 & Lancashire & 0.709 & 2,6 & 1 & 1,2 & decreasing & 0.722 \\
\hline 6 & Greater Manchester & 1.000 & 6 & 1 & 1,2 & constant & 1.000 \\
\hline 7 & Merseyside & 0.564 & 6 & 1 & 1 & decreasing & 0.586 \\
\hline 8 & Cheshire & 0.718 & $2,6,15$ & 1,2 & 1,2 & decreasing & 0.734 \\
\hline 9 & North Yorkshire & 0.786 & $2,6,15$ & 1,2 & 1,2 & decreasing & 0.791 \\
\hline 10 & West Yorkshire & 0.696 & 6 & 1 & 1 & decreasing & 0.700 \\
\hline 11 & Humberside & 0.482 & $2,6,15$ & 1,2 & 1,2 & decreasing & 0.500 \\
\hline 12 & South Yorkshire & 0.779 & 6,15 & 1,2 & 1 & decreasing & 0.794 \\
\hline 13 & Derbyshire & 0.618 & 2,6 & 1 & 1,2 & decreasing & 0.629 \\
\hline 14 & Nottinghamshire & 0.716 & 2,6 & 1 & 1,2 & decreasing & 0.730 \\
\hline 15 & Lincolnshire & 1.000 & 15 & 1,4 & 2 & constant & 1.000 \\
\hline 16 & Leicestershire & 0.812 & $2,6,15$ & 1,2 & 1,2 & decreasing & 0.820 \\
\hline 17 & Northamptonshire & 0.895 & 2,6 & 1 & 1,2 & decreasing & 0.895 \\
\hline 18 & Staffordshire & 0.791 & 2,6 & 1 & 1,2 & decreasing & 0.801 \\
\hline 19 & West Mercia & 0.769 & 2,6 & 1 & 1,2 & decreasing & 0.776 \\
\hline 20 & West Midlands & 0.846 & 6 & 1 & 1 & decreasing & 0.846 \\
\hline 21 & Warwickshire & 0.997 & 2,15 & 1,2 & 2 & decreasing & 0.997 \\
\hline 22 & North Wales & 0.725 & $2,6,15$ & 1,2 & 1,2 & decreasing & 0.732 \\
\hline 23 & Dyfed-Powys & 0.662 & 2,6 & 1 & 1,2 & decreasing & 0.671 \\
\hline 24 & Gwent & 0.783 & 6 & 1 & 1 & decreasing & 0.783 \\
\hline 25 & South Wales & 0.729 & 2, 6 & 1 & 1,2 & decreasing & 0.742 \\
\hline 26 & Norfolk & 0.658 & $2,6,15$ & 1,2 & 1,2 & decreasing & 0.667 \\
\hline 27 & Cambridgeshire & 0.715 & 2,6 & 1 & 1,2 & decreasing & 0.721 \\
\hline 28 & Suffolk & 0.798 & $2,6,15$ & 1,2 & 1,2 & decreasing & 0.798 \\
\hline 29 & Bedfordshire & 0.823 & 2 & 1 & 2 & decreasing & 0.823 \\
\hline 30 & Hertfordshire & 0.655 & 2,6 & 1 & 1,2 & decreasing & 0.659 \\
\hline 31 & Essex & 0.857 & $2,6,15$ & 1,2 & 1,2 & decreasing & 0.865 \\
\hline 32 & Gloucestershire & 0.639 & 6 & 1 & 1 & decreasing & 0.657 \\
\hline 33 & Avon \& Somerset & 0.496 & 2,6 & 1 & 1,2 & decreasing & 0.517 \\
\hline 34 & Wiltshire & 0.694 & $2,6,15$ & 1,2 & 1,2 & decreasing & 0.698 \\
\hline 35 & Devon \& Cornwall & 0.880 & $2,6,15$ & 1,2 & 1,2 & decreasing & 0.884 \\
\hline 36 & Dorset & 0.810 & $2,6,15$ & 1,2 & 1,2 & decreasing & 0.817 \\
\hline 37 & Thames Valley & 0.637 & 6 & 1 & 1 & decreasing & 0.644 \\
\hline 38 & Surrey & 0.584 & $2,6,15$ & 1,2 & 1,2 & decreasing & 0.598 \\
\hline 39 & Hampshire & 0.847 & 6,15 & 1,2 & 1 & decreasing & 0.854 \\
\hline 40 & Sussex & 0.618 & 2,6 & 1 & 1,2 & decreasing & 0.632 \\
\hline 41 & Kent & 0.650 & 2,6 & 1 & 1,2 & decreasing & 0.664 \\
\hline & mean & 0.749 & & & & & 0.756 \\
\hline & standard deviation & 0.128 & & & & & 0.123 \\
\hline
\end{tabular}


TABLE 3:

ANDERSEN-PETERSEN (1993) SUPER-EFFICIENCY SCORES FOR THREE FRONTIER POLICE SERVICES

\begin{tabular}{lcc}
\hline service & $\begin{array}{l}\text { Andersen-Peteresen super- } \\
\text { efficiency score input } \\
\text { orientation }\end{array}$ & $\begin{array}{l}\text { Andersen-Peteresen } \\
\text { super-efficiency score } \\
\text { output orientation }\end{array}$ \\
\hline 2 Durham & 1.502 & 0.666 \\
6 Greater Manchester & 1.412 & 0.708 \\
15 Lincolnshire & 6.817 & 0.147 \\
\hline
\end{tabular}


TABLE 4

EFFICIENCY SCORES AND DECOMPOSITION FOR 26 PROPOSED MERGERS

\begin{tabular}{|c|c|c|c|c|c|c|}
\hline merger & merger group & $\begin{array}{c}\mathrm{F}(\mathrm{J}) \\
\text { overall } \\
\text { index for } \\
\text { J merged } \\
\text { DMUs }\end{array}$ & $\begin{array}{l}\mathrm{F}(* \mathrm{~J}) \\
\text { index for } \\
\text { efficient } \\
\text { merged } \\
\text { DMUs }\end{array}$ & $\begin{array}{c}\mathrm{T}(\mathrm{J})= \\
\mathrm{F}(\mathrm{J}) / \mathrm{F}(* \mathrm{~J}) \\
\text { technical } \\
\text { efficiency } \\
\text { index }\end{array}$ & $\begin{array}{c}\mathrm{H}(\mathrm{J}) \\
\text { scope } \\
\text { index for } \\
\text { merged } \\
\text { DMUs }\end{array}$ & $\begin{array}{c}\mathrm{S}(\mathrm{J}) \text { size } \\
\text { index for } \\
\text { merged } \\
\text { DMUs }\end{array}$ \\
\hline 1 & 1_2_3 & 1.268 & 1.180 & 1.074 & 1.180 & 1.000 \\
\hline 2 & 4_5 & 1.436 & 1.436 & 1.000 & 1.436 & 1.000 \\
\hline 3 & 4_5_7 & 1.592 & 1.592 & 1.000 & 1.592 & 1.000 \\
\hline 4 & 6_8 & 1.109 & 1.109 & 1.000 & 1.109 & 1.000 \\
\hline 5 & 7_8 & 1.602 & 1.571 & 1.020 & 1.571 & 1.000 \\
\hline 6 & 9_10 & 1.466 & 1.466 & 1.000 & 1.466 & 1.000 \\
\hline 7 & 9_10_11_12 & 1.583 & 1.475 & 1.073 & 1.475 & 1.000 \\
\hline 8 & 11_12 & 1.585 & 1.585 & 1.000 & 1.585 & 1.000 \\
\hline 9 & 13_14 & 1.516 & 1.516 & 1.000 & 1.516 & 1.000 \\
\hline 10 & 18_19 & 1.282 & 1.282 & 1.000 & 1.282 & 1.000 \\
\hline 11 & 18_19_20_21 & 1.244 & 1.244 & 1.000 & 1.244 & 1.000 \\
\hline 12 & 20_21 & 1.219 & 1.219 & 1.000 & 1.219 & 1.000 \\
\hline 13 & 22_23_24_25 & 1.384 & 1.341 & 1.032 & 1.341 & 1.000 \\
\hline 14 & 26_27_28 & 1.423 & 1.329 & 1.071 & 1.329 & 1.000 \\
\hline 15 & 26_27_28_29_30_31 & 1.449 & 1.338 & 1.083 & 1.338 & 1.000 \\
\hline 16 & 26_28_31 & 1.229 & 1.161 & 1.059 & 1.161 & 1.000 \\
\hline 17 & 27_29_30 & 1.437 & 1.354 & 1.061 & 1.354 & 1.000 \\
\hline 18 & 29_30_31 & 1.464 & 1.394 & 1.051 & 1.394 & 1.000 \\
\hline 19 & 32_33_34_35_36 & 1.676 & 1.519 & 1.103 & 1.519 & 1.000 \\
\hline 20 & 32_33_34_36 & 1.715 & 1.592 & 1.077 & 1.592 & 1.000 \\
\hline 21 & 37_39 & 1.384 & 1.384 & 1.000 & 1.384 & 1.000 \\
\hline 22 & 38_39 & 1.211 & 1.211 & 1.000 & 1.211 & 1.000 \\
\hline 23 & 38_39_40 & 1.470 & 1.470 & 1.000 & 1.470 & 1.000 \\
\hline 24 & 38_40 & 1.683 & 1.683 & 1.000 & 1.683 & 1.000 \\
\hline 25 & 38_40_41 & 1.642 & 1.642 & 1.000 & 1.642 & 1.000 \\
\hline 26 & 40_41 & 1.576 & 1.576 & 1.000 & 1.576 & 1.000 \\
\hline
\end{tabular}

